\title{
Exploring the Quality of Life at the End of Life (QUAL-E) Instrument with Australian Palliative Care Hospital Patients: Hurdles and directions
}

\author{
Anne Wilkinson, Susan Slatyer, Kylie McCullough, and Anne Williams
}

\begin{abstract}
A Wilkinson (corresponding author): School of Nursing and Midwifery, Edith Cowan University, 270 Joondalup Drive, Joondalup, Western Australia 6027; anne.wilkinson@ecu.edu.au

S Slatyer: School of Nursing and Midwifery, Health Sciences, Curtin University, Perth, Western Australia, and Centre for Nursing Research, Sir Charles Gairdner Hospital, Perth, Western Australia, and School of Nursing and Midwifery, Edith Cowan University, Joondalup, Western Australia; K McCullough: School of Nursing and Midwifery, Edith Cowan University, Joondalup, Western Australia; A Williams: School of Nursing and Midwifery, Edith Cowan University, Joondalup, Western Australia and Sir Charles Gairdner Hospital, Perth, Western Australia
\end{abstract}

Keywords: ethics, palliative care, quality of life, end of life, hospital, patient experience, patient assessment, instrument development

Abstract / The provision of care that enhances the quality of life at the end of life is a fundamental goal of palliative care services. This pilot study explored the application of the Quality of Life at the End of Life (QUAL-E) instrument in a sample of 52 patients who were hospitalized in two metropolitan Western Australian hospitals. Participants were given the option to complete the QUAL-E either as a self-report ( $n=9,17.3$ percent) or, aided by a research assistant, as a structured interview ( $n=43,82.7$ percent). The instrument demonstrated patient acceptability and face validity, particularly when it was administered with the assistance of a research assistant. Despite having difficulty with some questions, patients expressed their appreciation at being given the opportunity to contribute to the research and to reflect upon and give voice to their thoughts and feelings. Health practitioners indicated that the instrument could be a valuable tool for holistic assessment and service evaluation. We suggest that minor changes be made to the QUAL-E before it is used further in an Australian context; we also recommend that this instrument be tested in other settings and populations.

Résumé / L'objectif fondamental des soins palliatifs est de dispenser des soins de santé qui améliorent la qualité de vie des malades en fin de vie. Notre projet pilote avait pour objectif d'évaluer le QUAL-E, un instrument de recherche destiné à connaître la qualité des soins de fin de vie chez 52 patients hébergés dans deux hôpitaux urbains en Australie occidentale. Les participants avaient deux choix: soit de remplir le questionnaire par eux-mêmes ( $n=9,17,3$ pourcent) ou soit de répondre au questionnaire sous une autre forme: un interview structuré, administré par un assistant de recherche ( $n=43,82,7$ pourcent). Cet instrument d'évaluation a été bien reçu et sa validité est apparente particulièrement lorsque conduite par l'assistant de recherche. En dépit du fait qu'ils ont eu de la difficulté à répondre à certaines questions, les patients ont exprimé leur appréciation d'avoir eu l'opportunité de contribuer à cette recherche et d'avoir pu réfléchir et exprimer leurs opinions et leurs propres sentiments. Les professionnels de la santé ont indiqué que cet instrument pourrait devenir un outil important pour faire une évaluation globale du malade et pour évaluer la qualité des soins dispensés. On suggère cependant de faire des modifications mineures au QUAL-E avant de l'utiliser en Australie. On recommande également d'en faire l'évaluation auprès d'autres groupes de patients et dans d'autres milieux.

\section{INTRODUCTION}

The journey toward the end of life is complex. Patients and their families confront challenges such as symptom control, physical and cognitive decline, psychosocial preparation for death, and frequent interactions with health services. Research on quality of life (QOL) at the end of life (EOL) has established that factors contributing to a "good death" for patients and their families include: "pain and symptom management, preparation for death, achieving a sense of completion, decisions about treatment preferences and being treated as a 'whole person'" (1, p. 2476). Despite the fact that most people wish to die at home (2), in Australia, more than half of all deaths occur in an inpatient hospital setting (3), and less than a third of patients dying in hospital have contact with palliative care services (PCS) $(4,5)$. 
Patients with a life-limiting illness benefit from involvement with PCS (6). This multidisciplinary, holistic approach to care offers support to patients and their families so that patients can live as actively as possible in whichever setting they prefer as they advance toward the EOL (7). PCS have been shown to improve patient outcomes in terms of physical and psychological symptom control, QOL, and use of hospital services (6). PCS access is no longer limited to cancer patients. Other terminally ill patients, such as those with heart failure or end-stage renal disease, are being referred to PCS for physical and emotional symptom management and support (7).

This paper reports on a pilot study that aimed to assess the suitability and feasibility of an instrument to measure QOL at the EOL in an Australian population. Previous research has defined the characteristics of QOL at the EOL from the perspectives of patients' family members and healthcare workers rather than from the perspective of patients themselves (8-10). Participating in research during the EOL period can be difficult for patients due to their declining physical and cognitive abilities and high symptom burden, and ethical considerations can also be an obstacle (11, 12). Furthermore, research into this phase of life is complicated by unpredictable illness trajectories. After a long period of slow decline, cancer patients often deteriorate rapidly near the EOL. However, those with other terminal illnesses may follow a more erratic pattern, with several episodes of decline followed by improvement, making it difficult to predict when death will occur (7). It can be hard to determine when someone has reached the EOL phase, which has been variously defined as ranging from the hours before death to the last year of life (5).

\section{METHODS}

Several instruments have been developed to measure QOL at the EOL, allowing interventions and models of care to be evaluated (13). These instruments are different from other QOL measures in that they place less emphasis on physical functioning and more on the patient's social and spiritual dimensions (13).

We considered the Quality of Life at the End of Life (QUAL-E) instrument to be a suitable one for assessing QOL at the EOL $(13,14)$. It was inductively developed from two focus group studies conducted with terminally ill patients, their carers, and health professionals, as well as a follow-up national survey (10). Psychometric testing of the QUAL-E has established the instrument's robustness across diverse sample groups with different disease trajectories and stability over time; it has also demonstrated the instrument's construct validity (15). Item reduction and factor analysis yielded an instrument with 21 questions covering four domains: symptom impact - identifying symptoms $(\alpha=0.87)$, relationship with the healthcare provider $(\alpha=0.71)$, preparation for the end of life $(\alpha=0.68)$, and life completion $(\alpha=0.8)$. A final, open-ended question was included to allow respondents to add any comments they might wish to make.

\section{Acceptability and Face Validity of the QUAL-E Instrument}

"Acceptability" refers to how well an instrument or intervention meets the needs of the target population and organizational setting. "Face validity" is a subjective evaluation of whether an instrument measures a construct of interest and provides insight into how participants might interpret and respond to the items the instrument contains (16). In this study, the acceptability and face validity of the QUAL-E was evaluated through instrument completion and field notes of researcher-participant interactions. Interviews with three senior PCS nurses were also conducted. These nurses were asked to describe how they selected patients for inclusion in the project, indicate what impact the research project had on daily practice, and identify any effects the research had on the patients involved. Interviews were audiotaped and transcribed verbatim prior to being analyzed.

\section{Study Sample}

The study population was comprised of patients receiving palliative care at two acute care public hospitals in Perth, Western Australia. At both study hospitals, patients could be referred to PCS for symptom control, discharge planning, or terminal care at any time during their hospitalization. PCS staff identified potential study participants during weekly team meetings. Others have undertaken a similar process (17). Senior clinical nurses within each hospital's PCS, in consultation with medical staff, identified eligible patients based on established criteria. Patients had to be older than 18, physically and emotionally able to participate, aware of their terminal prognosis, diagnosed with cancer or multiple organ failure but not dementia, currently admitted as an inpatient under the care of PCS in either of the two hospitals, and able to understand written and spoken English.

\section{Data Collection}

Potential participants identified by PCS were approached by a research assistant (RA) who introduced herself and explained that a research 
study was being conducted in the hospital to trial a questionnaire that could help patients provide information to PCS. The patients were informed that the questionnaire had been developed in the United States but had not yet been used in Australia. The RA explained that participation would involve patients completing the questionnaire either themselves (as a self-report) or with her assistance. She also told the patients that they would be invited to offer feedback about their experience of answering the QUAL-E questions. Interested patients were supplied with written information about the study and given the opportunity to ask questions. Those who were willing to participate were asked to provide their consent. Demographic data were taken from the patients' medical files to minimize the amount of time participants had to spend responding to the questionnaire.

One RA in each hospital administered the QUAL-E to enhance the fidelity of the data collection. A consistent approach to administering the instrument was developed, whereby the RA sat by the patient's bed holding the questionnaire to enable the patient to see the response sets. QUALE questions were asked and the patient's difficulties clarified in a consistent manner. Helping patients to complete the questionnaire allowed the RA an opportunity to assess the relative ease with which patients could answer the questions and thereby to identify problematic items. The RA invited feedback about the experience of completing the QUAL-E either after she had assisted patients to complete the instrument or after she had collected their self-reported responses. This feedback was documented in field notes.

\section{Ethical Considerations}

Ethics approval was granted by the supporting university and the two hospitals involved in the study. All potential participants were given an information sheet and a consent form to facilitate their provision of informed consent. In accordance with our recruitment procedures, and to enhance the process of obtaining informed consent, we included a family information form that participants could give to their interested relatives.

We encountered a number of hurdles during the ethical review of this study. The QUAL-E instrument is specifically designed for use with patients who have accessed a range of services and who have a variety of diagnoses, and our original intention was to include a wide population of patients. However, there was some concern that asking questions about palliative care and dying would cause these patients distress, particularly if they had been unaware of the terminal nature of their illness. For this reason, we only approached patients who were receiving PCS. There was also concern that we would not be able to identify a sufficient number of patients nearing death and still able to participate. However, the pilot nature of the study allowed us to explore the acceptability of administering the QUAL-E in this patient population.

\section{Analysis}

A coding template was used to record the number of times patients made comments (verbal or written) or omitted specific questions. The completed coding template is included as Table 1. This template helped us to identify questions that were problematic or lacked acceptability or validity. Field notes made of interactions with participants and audio recordings of interviews with the senior PCS nurses were transcribed verbatim. Two experienced researchers coded and analyzed the qualitative data independently and resolved any discrepancies through joint discussion.

\section{RESULTS}

The PCS identified a convenience sample of 78 patients who met the inclusion criteria. A total of 52 patients completed the questionnaire: 20 from hospital A, and 32 from hospital B (response rate: 67 percent). Male patients made up 44 percent of the sample, and the mean age of respondents was 67.35 years. Cancer was the primary diagnosis for 86 percent of the sample $(n=45)$, and noncancer diagnoses (such as cardiovascular disease, liver failure, end-stage renal disease, and other nonmalignancies) accounted for the rest. Length of stay ranged from 2 to 102 days, with a median stay of 5 days. Nine of the 52 participants (17.3 percent) chose to complete the QUAL-E as a self-report, while 43 (82.7 percent) accepted the offer of help from the RA and completed the questionnaire as a structured interview.

\section{Problematic Questions}

A total of 40 respondents (77 percent) completed all items on the QUAL-E questionnaire. Unanswered questions were most often those concerned with symptom impact (questions 1-4), patients' relationship with the healthcare provider (questions 5-9), patients' positive difference in the lives of others (question 15), and patients' sense of meaning in their lives (question 18). There were 2 patients who did not answer the question about overall QOL (question 21); 15 were unable to identify more than two bothersome physical symptoms (questions 1-4) and 4 of the 9 patients who self-administered the instrument left the symptom impact questions (questions 1-4) blank. 
Table 1 / Coding Template for the Quality of Life at the End of Life (QUAL-E) Study

\begin{tabular}{|c|c|c|c|c|}
\hline QUAL-E: A measure of quality of life at the end of life & \begin{tabular}{c|} 
Required \\
interpretation
\end{tabular} & $\begin{array}{l}\text { Verbal } \\
\text { comment }\end{array}$ & $\begin{array}{l}\text { Emotional } \\
\text { response }\end{array}$ & \multirow{2}{*}{$\begin{array}{c}\begin{array}{c}\text { Incomplete } \\
\text { data }\end{array} \\
\text { Self-report }\end{array}$} \\
\hline Question & \multicolumn{3}{|c|}{ Field notes } & \\
\hline Symptom impact - identifying symptoms & 3 & 3 & & \\
\hline $\begin{array}{l}\text { 1. During the last week, how often have you experienced } \\
\text { [symptom]? }\end{array}$ & & 2 & & 4 \\
\hline $\begin{array}{l}\text { 2. During the last week, on average, how severe has } \\
\text { [symptom] been? }\end{array}$ & 1 & & & 4 \\
\hline $\begin{array}{l}\text { 3. During the last week, how much has [symptom] interfered } \\
\text { with your ability to enjoy your life? }\end{array}$ & & 2 & & 4 \\
\hline $\begin{array}{l}\text { 4. How worried are you about [symptom] occurring } \\
\text { in the future? }\end{array}$ & 1 & 1 & & 4 \\
\hline \multicolumn{5}{|l|}{ Relationship with the healthcare provider } \\
\hline $\begin{array}{l}\text { 5. Although I cannot control certain aspects of my illness, } \\
\text { I have a sense of control about my treatment decisions. }\end{array}$ & 2 & 3 & & 2 \\
\hline $\begin{array}{l}\text { 6. I participate as much as I want in the decisions } \\
\text { about my care. }\end{array}$ & 2 & 1 & & 2 \\
\hline $\begin{array}{l}\text { 7. Beyond my illness, my doctor has a sense of who I am } \\
\text { as a person. }\end{array}$ & 2 & 8 & & 1 \\
\hline $\begin{array}{l}\text { 8. In general, I know what to expect about the course } \\
\text { of my illness. }\end{array}$ & & 3 & & 1 \\
\hline $\begin{array}{l}\text { 9. As my illness progresses, I know where to go to get answers } \\
\text { to my questions. }\end{array}$ & & 3 & & \\
\hline \multicolumn{5}{|l|}{ Preparation for the end of life } \\
\hline 10. I worry that my family is not prepared to cope with the future. & 2 & & 1 & \\
\hline 11. I have regrets about the way I have lived my life. & & 1 & & 1 \\
\hline \multicolumn{5}{|l|}{ 12. At times, I worry that I will be a burden to my family. } \\
\hline 13. I worry about the financial strain caused by my illness. & & 1 & & \\
\hline 14. I have been able to say important things to those close to me. & 3 & 2 & & \\
\hline \multicolumn{5}{|l|}{ Life completion } \\
\hline 15. I make a positive difference in the lives of others. & 2 & 2 & & 4 \\
\hline $\begin{array}{l}\text { 16. I have been able to help others through time together, gifts, } \\
\text { or wisdom. }\end{array}$ & 2 & 1 & & \\
\hline 17. I have been able to share important things with my family. & 0 & 1 & & 1 \\
\hline 18. Despite my illness, I have a sense of meaning in my life. & 6 & 6 & & \\
\hline 19. I feel at peace. & & 2 & & \\
\hline $\begin{array}{l}\text { 20. There is someone in my life with whom I can share } \\
\text { my deepest thoughts. }\end{array}$ & & 3 & 2 & \\
\hline 21. How would you rate your overall quality of life? & & 2 & & 2 \\
\hline
\end{tabular}

Source: Steinhauser, Clipp, Bosworth, et al. (13).

A number of respondents had sought help to understand the meaning of questions related to physical symptoms and abstract concepts. It was evident that their fluctuating symptoms, the psychosocial impact of their illness, and the number of people involved in their care made it difficult for some patients to quantify physical symptoms. The strength of their relationships with members of the healthcare team was also difficult for them to determine. In addition, a number of patients 
vided insight into the sources of participants' difficulties.

\section{Relationship with the healthcare provider}

A total of 12 of the 23 interview respondents (52 percent) had questions or comments related to this domain. They appeared to be confused as to which doctor was being referred to in the question about whether the doctor seemed to have a sense of who the patient was as a person (question 7). Many respondents referred to their general practitioners when the instrument was intended to extract information about PCS doctors. Participants also noted that they had several doctors, many of whom were part of a large team whose individual members only saw them briefly.

In addition, four patients needed assistance with question 5 , which asked about control over the illness and treatment decisions. Participants needed the RA to clarify what was meant by "control" and explain which of their treatments should be assessed in this respect. For example, one respondent had difficulty quantifying her sense of control because she was "not having any treatment at that time and therefore there [were] no decisions to be made." Another respondent remarked that she had a number of different doctors; with some, she felt in control, but with others she did not. It was also evident that the complexity of care made it difficult for some respondents to determine whether the doctor "has a sense of who I am as a person" (question 7).

\section{Preparation for the end of life}

Two respondents needed clarification of the Likert scale response levels, and one respondent, when asked about regrets in life (question 11), was unable to answer, despite receiving assistance from the RA. Another became emotional when this question about regrets caused her to consider the burden her condition placed on her family. Yet another reflected on her family's financial future now that she was unable to work; with her permission, the RA asked the PCS to follow-up on this. Three respondents did not understand the question about saying important things to those close to them (question 14). One considered it the most "unusual question...I have ever been confronted with," while another contextualized the question by saying, "I give advice to those around me."

\section{Life completion}

Questions in the life completion domain raised the most issues among participants. Many asked for help to understand what, for them, was an abstract concept, or they made comments indicating that these questions raised transcendental con- cerns. A question about helping others through time together, gifts, or wisdom (question 16) confused some respondents; one participant was unable to answer it until his wife remarked that he had recently received a letter from a family member regarding this very thing. Another said, "That sounds religious to me." Three questions referring to communication with "those close to me" (question 14), "my family" (question 17), and "someone in my life" (question 20) were considered to be, as one PCS nurse put it, duplicative because "family is the most important thing to most people." Lastly, a question probing patients' sense of having someone with whom they could share their deepest thoughts (question 20) evoked emotional responses from respondents as they described supportive family members or friends.

\section{Acceptability of the QUAL-E Instrument to Western Australian Palliative Care Patients}

While participants demonstrated some difficulties with particular domains, their overall responses indicated that completing the QUAL-E was a positive experience for them. A number of patients expressed eagerness to finish the interview despite interruptions. While some patients found the questions "easy," some also used descriptors such as "thoughtful," "interesting," and "sensible." One participant commented that the questions "were not superficial," adding, "Superficial questions would be an insult." Data collected from the PCS nurses revealed that there had been no negative feedback from patients and no evidence that they had experienced lasting emotional distress as a result of their participation. The questionnaire took between 15 and 25 minutes to complete. One patient felt exhausted by it; another stated that he didn't think the questionnaire applied to him, as he didn't consider himself to be at the end stage yet.

\section{Assistance with Completion}

One aspect of this study was a consideration of how feasible it was to conduct research in an inpatient PCS. The RAs reported that there were numerous interruptions during the completion of the questionnaires, but this did not seem to adversely affect the process.

All of the participants at hospital A and 23 participants at hospital B requested the RA's assistance for a variety of reasons. Some wanted help because they had physical limitations such as poor vision or lethargy; others needed emotional support. One participant remarked, "I couldn't do it on my own." At times, the RA would have to explain certain questions or use simpler English to help participants understand. For the demographic questions, the RA sometimes had to deter- 
mine participants' education levels, as many respondents were elderly and could not convert the grade levels of the school system of their day into contemporary grade levels. Some participants required prompting when asked to describe bothersome symptoms such as pain, nausea, or fatigue.

On three occasions, the RA noticed that the participant was becoming emotional when answering particular questions. Each time, the RA offered comfort and volunteered to stop, but all three patients asked to continue with the questionnaire. The RA informed the PCS nurse of the patients' distress. On another occasion, the RA facilitated an information flow, with the patient's consent, between a patient and PCS when the patient disclosed that she was concerned about going home as she lived in a rural area where few services were available.

\section{PCS Nurse Interviews}

Thematic analysis of data collected from the PCS nurses revealed that in determining a patient's suitability for inclusion in the study, the nurses primarily considered the patient's cognitive ability, level of symptom burden, and likelihood of becoming emotionally distressed. Data from the nurse interviews on the applicability of the QUAL-E in clinical practice revealed that, due to its holistic nature, the instrument was perceived as a particularly useful tool for assessing patients' emotional status or for prompting patients to voice their concerns as the EOL approached. This suggests that the QUAL-E could also be used by social workers to identify and address psychosocial issues. The perceived barriers to using the instrument in practice related to a lack of staff time to administer the QUAL-E as an interview. The PCS nurses were also concerned that using the instrument would raise problems that clinicians did not have the resources to resolve: "[With] some of the questions, we'd need to be careful that we can respond to them." They thought that it might be best to give the questionnaire to patients to complete themselves at a time conducive to self-reflection or to administer it in an abridged format.

\section{DISCUSSION}

The results of this study support the acceptability of the QUAL-E to this sample of Western Australian hospitalized palliative care patients. A striking finding was that the interview application of the QUAL-E generated broader and more detailed responses to important aspects of care than the self-administered instrument. Most interview respondents understood the questions and could answer within the response sets, but patients' unsolicited comments suggested that a number of items prompted descriptions of important existential or psychosocial concerns that could be addressed by PCS. While the interview option was designed to facilitate participation, it provided an unexpected opportunity to identify EOL problems, such as financial strain or lack of rural services, which may not have been addressed during hospitalization.

This study demonstrated that, due to the complexity and fluctuating nature of their symptoms, patients encountered difficulties when asked to selectively quantify their physical experiences. Their difficulties were compounded by their confusion over the format of the symptom-impact questions, which shifted focus from the previous month to the last week.

The degree to which patients at the EOL feel that they are seen as a whole person by their healthcare providers and are being kept informed about treatment decisions are crucial aspects of high-quality care (13). The fact that the RAs were often required to help respondents contextualize items related to their relationships with their healthcare providers indicated that the questions in this domain should be adjusted for an Australian population. Amending the instrument by including a clarifying note such as, "My [oncologist/ palliative care team/general practitioner] sees me as a whole person" could be useful in the Australian context.

Most problematic for participants were questions about meaning and positive contributions to others. Meaning in life is a construct that is positively correlated to happiness and life satisfaction (18). Some participants understood meaning to be related to legacy, while others linked it to functional ability or spirituality. One way to guide respondents in considering this abstract concept would be to add to the QUAL-E a glossary of prompts such as: "Meaning is 'the sense made of, and significance felt regarding, the nature of one's being and existence'" $(18$, p. 81$)$. Our findings indicate that further research is merited to develop an understanding of meaning as a concept that can be articulated by patients at the EOL.

Patients' difficulty with some items may have been compounded by the confusion they felt when presented with questions that involved a shift between past and present. This may be particularly problematic for patients at an early stage of the palliative care journey. For example, question 17 reads, "I have been able to share important things with my family," and not, "I am able to share important things with my family." Also, it is 
not clear whether the final question - "How would you rate your overall quality of life?" refers to respondents' QOL at the time they completed the questionnaire or their QOL as a whole.

Clinicians' concerns about having to address problems raised and identified by the questionnaire must be acknowledged. If the QUAL-E is to be used as a patient assessment or screening tool, then it needs to be supported with an action plan and staff education on how to address any problems that arise - for example, staff should be told what services and supports to suggest to patients who indicate that they are under financial strain.

In considering the feasibility of administering and processing the instrument (19), we concluded that it was likely that having an RA on hand to answer participants' questions and assist those who felt unable to self-administer the questionnaire increased participation in the study. Approximately 83 percent of participants requested that the RA administer the QUAL-E, often due to their physical limitations or general weakness. In addition, the RA often needed to explain to participants the abstract concepts raised in some of the questions or articulate questions in simpler English. Patients who felt ill or sleepy did not have sufficient concentration to grasp intangible ideas. Moreover, the RA provided support or referrals for patients who became emotional in responding to certain questions; the RA also communicated to PCS any concerns or needs participants had that PCS could address.

We anticipated that responding to the QUAL-E would sometimes be stressful for hospitalized patients who were dealing with EOL issues. Both of the RAs employed to collect the data were registered nurses. One had recent acute hospital experience and the other was working within PCS. Both were alert to the possibility that patients could become upset, and they were ready to provide emotional support as needed. Any participant who became emotional was given the option to stop the interview. However, all chose to continue when the emotional moment had passed. While no information from the QUAL-E responses was routinely provided to clinical staff, the PCS nurses were informed about any patients who had expressed upset or disclosed psychosocial concerns. The RAs had a clearly defined role as researchers only, not as therapists; however, participants in previous research conducted at the EOL have found that the opportunity to discuss difficult issues related to death and dying is "therapeutic, cathartic, educational, empowering, altruistic and social" (20, p. 173).

While we can expect patients in the EOL period to become emotional when speaking about death and dying, it is not always clear to those who develop research questionnaires which questions will prompt such a response. In assisting participants to complete the QUAL-E questionnaire we had an ideal opportunity to identify these questions and thus to develop strategies to minimize the risk of prompting emotional responses (21). We developed a protocol for dealing with patient distress, and we ensured that our RAs had experience and training in identifying verbal and nonverbal indicators of that distress.

We also found that by employing an RA to help participants complete the questionnaire, we were able to minimize disruption in the inpatient environment and the demands on staff. With sufficient time and flexibility, the RA could tailor data collection to accommodate each patient's condition and the demands of clinical care. A recent study (22) proposes that the QUAL-E questionnaire be reduced to 17 items in four domains.

\section{LIMITATIONS}

A limitation of this study was that by nominating patients to participate in it, PCS were interested in protecting the most vulnerable. Consequently, our results may not reflect the experiences of all PCS users. While the QUAL-E is designed for use with patients who "may or may not have acknowledged the terminal nature of their disease" (13, p. 830), we were unable to pilot the instrument with patients who were not already using PCS. Delayed access to PCS may deny patients the opportunity to participate in decision making and to prepare for death before experiencing significant physical and cognitive decline (23). Our findings demonstrate that exploration of patients' QOL at the EOL using an instrument such as the QUAL-E can help to identify problems that are amenable to intervention, particularly when the instrument is administered as an interview.

There is no doubt that patients who are at the EOL are vulnerable and need to be offered additional protection by ethics committees (11). Nevertheless, our finding that patients often experience some benefit from participating in research at the EOL supports the initiative to conduct further studies. Such inquiry could inform healthcare education and practice and facilitate timely referral to PCS, particularly for noncancer patients (6, $7,23)$.

\section{CONCLUSION}

This study highlights the importance of pilot testing instruments thoroughly. Despite rigorous psychometric analysis of the instrument, our study revealed that some patients experienced difficulties while completing the QUAL-E question- 
naire. Providing a trained RA to assist those patients should be included in the methodology of instrument development and testing. We consider this instrument to be a potentially valuable screening tool for conducting holistic patient assessments that encompass the physical, psychological, emotional, and social aspects of a patient's journey at the EOL. However, clinicians' statements about the problems they may have in addressing patients' concerns must be acknowledged.

QOL at the EOL is the primary goal of PCS; however, the experience of patients in this stage of life is under researched because it is difficult to access this population. It is imperative that we conduct studies that meet the requirements of ethics committees. However, it is also important that we offer patients the opportunity to benefit from participation in research and allow society to benefit from the results of research - particularly that related to QOL and service or program evaluation. The QUAL-E questionnaire may prove to be an important tool for evaluating PCS, but if it is to become so the sample of respondents must be representative of the service population. It is therefore vital that we facilitate researchers' access to vulnerable patients at the EOL from culturally and linguistically diverse backgrounds.

\section{ACKNOWLEDGEMENTS}

This project was funded by the Cancer and Palliative Care Research and Evaluation Unit, The University of Western Australia. The authors would like to thank the palliative care services at Sir Charles Gairdner Hospital and the Royal Perth Hospital, and, in particular, Dr. Doug Bridge and Dr. Anil Tandon, as well as June Gorringe, Natalie Panizza, and Karen Proctor. We also acknowledge Helen Walker from the Western Australian Cancer and Palliative Care Network, Dr. Derrick Lopez, and Natasha Long for their contributions.

Received: May 13, 2013

Final version accepted: September 19, 2013

\section{REFERENCES}

1. Steinhauser KE, Christakis NA, Clipp EC, et al. Factors considered important at the end of life by patients, family, physicians, and other care providers. JAMA 2000; 284(19): 2476-2482.

2. Giesinger JM, Wintner LM, Oberguggenberger AS, et al. Quality of life trajectory in patients with advanced cancer during the last year of life. J Palliat Med 2011; 14(8): 904-912.

3. Australian Institute of Health and Welfare. Trends in palliative care in Australian hospitals - key findings. Canberra: author; 2007. Accessed August 12, 2012. www.aihw.gov.au/palliativecare-key-findings
4. Wilcoxon H, Luxford K, Saunders C, et al. Multidisciplinary cancer care in Australia: a national audit highlights gaps in care and medico-legal risk for clinicians. Asia Pac J Clin Oncol 2011; 7(1): 34-40.

5. Bennett MI, Davies EA, Higginson IJ. Delivering research in end-of-life care: problems, pitfalls and future priorities. Palliat Med 2010; 24(5): 456-461.

6. Higginson IJ, Evans CJ. What is the evidence that palliative care teams improve outcomes for cancer patients and their families? Cancer J 2010; 16(5): 423-435.

7. Department of Health, Western Australia. Palliative care model of care. Perth: WA Cancer and Palliative Care Network, Department of Health, Western Australia; 2008. Accessed December 28, 2013. www.healthnetworks.health.wa.gov.au/ modelsofcare/docs/Palliative_Care_Model_of_Care.pdf

8. Addington-Hall J, McPherson C. After-death interviews with surrogates/bereaved family members: some issues of validity. J Pain Symptom Manage 2001; 22(3): 784-790.

9. Neergaard M, Olesen F, Jensen A, et al. Palliative care for cancer patients in a primary health care setting: bereaved relatives' experience, a qualitative group interview study. BMC Palliat Care 2008; 7: 1.

10. Steinhauser KE, Clipp EC, McNeilly M, et al. In search of a good death: observations of patients, families and providers. Ann Intern Med 2000; 132(10): 825-832.

11. Whiting LS, Vickers PS. Conducting qualitative research with palliative care patients: applying Hammick's research ethics wheel. Int J Palliat Nurs 2010; 16(2): 58-68.

12. Lee S, Kristjanson L. Human research ethics committees: issues in palliative care research. Int J Palliat Nurs 2003; 9(1): 13-18.

13. Steinhauser KE, Bosworth HB, Clipp EC, et al. Initial assessment of a new instrument to measure quality of life at end of life. J Palliat Med 2002; 5(6): 829-841.

14. Steinhauser KE, Clipp EC, Bosworth HB, et al. Measuring quality of life at the end of life: validation of the QUAL-E. Palliat Support Care 2004; 2(1): 3-14.

15. Albers G, Echteld MA, de Vet HC, et al. Evaluation of qualityof-life measures for use in palliative care: a systematic review. Palliat Med 2010; 24(1): 17-37.

16. DeVon HA, Block ME, Moyle-Wright $P$, et al. A psychometric toolbox for testing validity and reliability. J Nurs Scholarsh 2007; 39(2): 155-164.

17. Tan H, Wilson A, Olver I, et al. Recruiting palliative patients for a large qualitative study: some ethical considerations and staff dilemmas. Explore 2010; 6(3): 159-165.

18. Steger MF, Frazier P, Oishi S, et al. The Meaning in Life Questionnaire: assessing the presence of and search for meaning in life. J Counseling Psychol 2006; 53(1): 80-93.

19. Fitzpatrick R, Davey C, Buxton MJ, et al. Evaluating patientbased outcome measures for use in clinical trials. Washington: US Department of Health and Human Services; 1998.

20. Alexander SJ. "As long as it helps somebody": why vulnerable people participate in research. Int J Palliat Nurs 2010; 16(4): 174-179.

21. National Health and Medical Research Council. National statement on ethical conduct in human research. Canberra: Australian government; 2007. Accessed December 28, 2013. www.nhmrc.gov.au/_files_nhmrc/publications/attachments/ e72.pdf

22. Lo C, Burman D, Swami N, et al. Validation of the QUAL-EC for assessing quality of life in patients with advanced cancer. Eur J Cancer 2011; 47(4): 554-560.

23. Thompson GN, McClement SE, Daeninck PJ. "Changing lanes": facilitating the transition from curative to palliative care. J Palliat Care 2006; 22(2): 91-98. 
Reproduced with permission of the copyright owner. Further reproduction prohibited without permission. 